\title{
Triazine-Acceptor-Based Green Thermally Activated Delayed Fluorescence Materials for Organic Light-Emitting Diodes
}

\author{
Ramanaskanda Braveenth $\$ and Kyu Yun Chai *๑1 \\ Division of Bio-Nanochemistry, College of Natural Sciences, Wonkwang University, Iksan City 570-749, \\ Chonbuk, Korea \\ * Correspondence: geuyoon@wonkwang.ac.kr; Tel.: +80-63-850-6230
}

Received: 22 June 2019; Accepted: 19 August 2019; Published: 20 August 2019

\begin{abstract}
High-efficiency thermally activated delayed fluorescence (TADF) is leading the third-generation technology of organic light-emitting diodes (OLEDs). TADF emitters are designed and synthesized using inexpensive organic donor and acceptor derivatives. TADF emitters are a potential candidate for next-generation display technology when compared with metal-complex-based phosphorescent dopants. Many studies are being conducted to enhance the external quantum efficiencies (EQEs) and photoluminescent quantum yield of green TADF devices. Blue TADF reached an EQE of over $35 \%$ with the support of suitable donor and acceptor moieties based on a suitable molecular design. The efficiencies of green TADF emitters can be improved when an appropriate molecular design is applied with an efficient device structure. The triazine acceptor has been identified as a worthy building block for green TADF emitters. Hence, we present here a review of triazine with various donor molecules and their device performances. This will help to design more suitable and efficient green TADF emitters for OLEDs.
\end{abstract}

Keywords: Triazine; TADF; Delayed time; green OLED

\section{Introduction}

Organic light-emitting diodes (OLEDs) and the application of organic materials in emitting technology have attracted much attention from industrial and research communities since 1987. The advantages of OLED technology, such as its light weight, image quality, high contrast, fast response time, thin film, and wide-view angle, have made it a potential candidate in commercial applications instead of liquid crystal displays (LCDs) [1-5]. Moreover, OLED displays can be fabricated on foldable and bendable substrates, thus making them a leading type of next-generation display. OLEDs have received considerable attention as an energy-efficient technology because they do not require any backlighting support [6-8]. OLED technology has developed from single- to multilayer devices across three generations of dopant materials. Multilayer OLED devices consist of several layers between an anode and a cathode, including a hole-injection layer (HIL), a hole-transporting layer (HTL), an electron-blocking layer (EBL), an emission layer (EML), a hole-blocking layer (HBL), an electron-transporting layer (ETL), and an electron-injection layer (EIL). The emission layer is made of two components, namely, host and dopant materials. The dopant material, at a suitable doping concentration, is usually doped with a high-triplet energy host material to support effective energy balance and emit colors by a proper charge recombination [9-19].

The spin rule explains the singlet and triplet emission possibilities of OLED dopants, where $25 \%$ are only responsible for singlet emission while $75 \%$ are from the triplet state. First-generation fluorescent emitters harvest only singlet emission with an internal quantum efficiency (IQE) of $25 \%$. The remaining 
$75 \%$ of the IQE does not hold any emission responsibility for colors [20-25]. Phosphorescent OLEDs (PhOLEDs) were developed by using iridium- and platinum-based noble metals to enable the $100 \%$ IQE by activating the intersystem crossing (ISC) pathway [26-32]. The efficiency of PhOLEDs was enhanced further by developing various host materials. Host materials are responsible for supplying energy to the dopant while preventing energy flow back from the dopant [33-37]. The major disadvantage of PhOLEDs is that they require the use of expensive noble metals to form a metal-ligand complex, which produces toxic waste [38-43].

Current studies are exploring new technologies using metal-free dopants and a type of emission referred to as thermally activated delayed fluorescence (TADF). This TADF mechanism can also achieve $100 \%$ IQE by activating an efficient up-conversion process of reverse intersystem crossing (RISC) from an excited triplet state to an excited singlet state [44-51]. The TADF concept is based on organic molecules with suitable donor-acceptor building blocks. Donor and acceptor moieties present in the same molecule enable intramolecular charge transfer (ICT) with a small energy difference between singlet and triplet excited states to allow an effective RISC process to harvest singlet emissions through converting triplets to singlets. Moreover, clear separation between highest occupied molecular orbitals and lowest unoccupied molecular orbital (HOMO and LUMO) distribution, twisted molecules, and a phenyl linker between donor and acceptor support an effective TADF mechanism that can achieve highly efficient device performances [52-60].

Many donor-acceptor-based structures have been reported for TADF emitters. The most commonly reported donor moieties are carbazole, diphenylamine, acridine, phenoxazine, phenothiazine, and their derivatives. The electron-withdrawing groups of cyano, boron, pyridine, pyrimidine, triazine, sulfone, dicyanofluorene, pyrazine, and ketone have been employed as acceptor moieties [61-66]. Suitable donor and acceptor combinations create efficient TADF emitters and help to decrease the singlet-triplet energy gap, which increases the rate constant of RISC. According to Boltzmann's equation, increasing the rate of ISC and RISC helps to decrease the delayed fluorescence time. Over the past few years, great advances have been made in the efficiencies of red, green, and blue color development $[67,68]$.

The external quantum efficiencies (EQEs) of red, green, and blue TADF OLEDs have made great progress along with new molecular designs. Red emitters suffer due to low band-gap energy and longer wavelengths near the IR region. Recently, green TADF emitters have received much attention because of their molecular design and efficiency enhancement. Strong-donor-weak-acceptor, weak-donor-strong-acceptor, and moderate-donor-moderate-acceptor combinations were identified and applied to green TADF molecular constructions [66,69-71]. Acridine, phenoxazine, and phenothiazine are strong donor groups, and boron and sulfone derivatives are strong withdrawing groups. The color purity of emitters was controlled according to the type and number of donor moieties attached with different positions of linker units present between donor and acceptor moieties. Among the reported cyano-acceptor-based green TADF emitters, $4 \mathrm{CzIPN}$ exhibited good device characteristics. The EQEs of 4 CzIPN green emitters were $14 \%, 19.3 \%, 21.8 \%, 26.5 \%, 27.5 \%, 26.7 \%, 28.6 \%, 29.6 \%$, and $31.2 \%$ with various host materials of $\mathrm{mCBP}, \mathrm{CBP}, 4 \mathrm{CN} 34 \mathrm{BC}, \mathrm{mCPSOB}, \mathrm{mCP}: \mathrm{TSPO} 1, \mathrm{DCzDCN}$, $\mathrm{mCP}: \mathrm{BmPyPb}, \mathrm{mCP}: \mathrm{B} 3 \mathrm{PYMPM}$, and 3CzPFP, respectively [72-79]. The weak electron acceptor of the pyrazine moiety with different donor-derivative-based green TADF emitters exhibited low device characteristics, but pyrimidine-based Ac-HPM, Ac-PPM, and Ac-MPM revealed considerable EQEs of $20.9 \%, 19.0 \%$, and $24.5 \%$, respectively [80]. A thioxanthone acceptor unit with carbazole (TXO-PhCz) and triphenylamine (TXO-TPA) donor derivatives showed EQEs of $21.5 \%$ and $18.5 \%$, respectively, and the efficiencies were better than those of pyrazine-based green TADF emitters [59]. The stable and moderate electron-withdrawing triazine molecule showed great efficiencies and improved device stabilities. The boron-acceptor-based green TADF emitters PXZ-Mes ${ }_{3} \mathrm{~B}$ and $2 \mathrm{DAC}-\mathrm{Mes}_{3} \mathrm{~B}$ revealed EQEs of $22.8 \%$ and $21.6 \%$, respectively, which were higher than those of thioxanthone-based green emitters [69]. A triazine acceptor with different donor moieties of TmCzTrz, DMAC-TRZ, TRZ-DDPAc, and DACT-II had excellent EQEs of $25.5 \%, 26.5 \%, 27.3 \%$, and $29.6 \%$, respectively, and the 
current efficiencies of acridine-donor-based DMAC-TRZ and TRZ-DDPAc were 66.8 and $62.8 \mathrm{~cd} / \mathrm{A}$, respectively [81-84].

When we compare the device efficiencies of various acceptor-based green TADF emitters, the triazine acceptor with suitable donor moieties enhances the device efficiencies and photoluminescent quantum yield (PLQY). In this review, we focus on triazine-based green TADF emitters and their device characteristics. As a moderate acceptor, triazine is an interesting derivative for green TADF emitters. Triazine-based green TADF emitters are depicted in Figures 1-6, and their photophysical properties and device performances are summarized in Tables 1 and 2, respectively.

\section{Results and Discussion}

The heterocyclic triazine acceptor is a well-known moiety for green TADF emitters due to its stable and moderate electron acceptability. Many studies have reported that efficient green TADF emitters were developed by replacing various donor moieties in different positions and suitable device structures, especially the host material.

12,12' -(6-([1,1'-biphenyl]-4-yl)-1,3,5-triazine-2,4-diyl)bis(11-phenyl-11,12 dihydroindolo[2,3a] carbazole) (PIC-TRZ) (Figure 1) was developed with two steric indolocarbazole donor units to confine the pi conjugation, which helped to reduce the singlet-triplet energy gap through clear frontier molecular orbital separation [85]. The PLQY was reported to be $39 \%$ and had a delayed fluorescence time of $230 \mu$ s. This OLED device was fabricated with $\mathrm{mCP}$ host material, which has a high-triplet energy of $2.91 \mathrm{eV}$, to ensure effective energy transfer from the host to the dopant. The electroluminescent emission was recorded at $500 \mathrm{~nm}$ and the EQE was 5.3\%. The monosubstituted donor-based 12-(4,6-diphenyl-1,3,5-triazin-2-yl)-5-phenyl-5,12-dihydroindolo[3,2-a]carbazole (PIC-TRZ2) not only had a lower singlet-triplet energy difference of $0.02 \mathrm{eV}$ compared with PIC-TRZ but also showed a high quantum yield of $45 \%$. The EQE was boosted from $5.3 \%$ to $14 \%$ with an effective reverse intersystem crossing [86].

Lee et al. reported another molecule with a disubstituted bicarbazole donor derivative at the second and fourth positions of the triazine acceptor. 9,9' -(6-phenyl-1,3,5-triazine-2,4-diyl)bis((9H-3,9' -bicarbazole)) (CC2TA) (Figure 1) showed a low energy difference of $0.05 \mathrm{eV}$ between the singlet and triplet levels, which was supported by the considerable separation between the donor and acceptor units. A photoluminescent quantum yield of $62 \%$ was recorded, while delayed fluorescence was observed at $22 \mu \mathrm{s}$. This OLED device was constructed using a double emission layer with host materials such as $\mathrm{mCP}$ and DPEPO. The double-layered host materials were responsible for opposite charge transportation, and a thin layer of DPEPO was employed to block excitons at the interface between the emission layer and the electron-transporting layer. The device exhibited an external quantum efficiency of $11 \%$ and an emission of $490 \mathrm{~nm}$ [87].

The carbazole-triazine based 9-(4,6-diphenyl-1,3,5-triazin-2-yl)-9'-phenyl-9H,9' H-3,3'-bicarbazole (CzT) (Figure 1) molecule showed a PLQY of around $40 \%$, and the singlet-triplet energy gap was observed to be $0.07 \mathrm{eV}$. This OLED device was fabricated with the high-triplet energy host material DPEPO to ensure effective energy transfer. Also, a low concentration of $3 \mathrm{wt} \% \mathrm{CzT}$ was applied during the fabrication process to prevent fluorescence quenching at the emission layer. The power and EQE were $9.7 \mathrm{~lm} / \mathrm{W}$ and $6 \%$, respectively, and electroluminescent emission was recorded at $520 \mathrm{~nm}$. Additionally, a biphenyl link between the triazine acceptor and carbazole donor for the 3-(2'-(4,6-diphenyl-1,3,5-triazin-2-yl)-[1,1'-biphenyl]-2-yl)-9-phenyl-9H-carbazole (PhCzTAZ) molecule (Figure 1) displayed a higher singlet-triplet energy gap and made an impossible reverse intersystem crossing, which did not show any delayed component in photophysical evaluation [88].

Lee et al. studied triazine-based TADF emitters with an increased number of carbazole donor moieties, which were attached with a phenyl linker unit (Figure 1). 9, $9^{\prime}, 9^{\prime \prime}$-(5-(4,6-diphenyl-1,3,5triazin-2-yl)benzene-1,2,3-triyl)tris(3,6-dimethyl-9H-carbazole) (TmCzTrz) and 9,9'-(2-(3,6-dimethyl9H-carbazol-9-yl)-5-(4,6-diphenyl-1,3,5-triazin-2-yl)-1,3-phenylene)bis (9H-carbazole) (DCzmCzTrz) revealed PLQYs of $100 \%$ and $98 \%$, respectively, and the energy difference between the singlet and triplet 
states were 0.07 and $0.20 \mathrm{eV}$, respectively. The higher PLQY of the TmCzTrz molecule showed greater efficiencies $(18.6 \mathrm{~cd} / \mathrm{A}, 52.1 \mathrm{~lm} / \mathrm{W}$, and $25.5 \%)$ than the DCzmCzTrz molecule. The number of carbazole donors with even HOMO distribution increased, and the device efficiencies were enhanced [89].

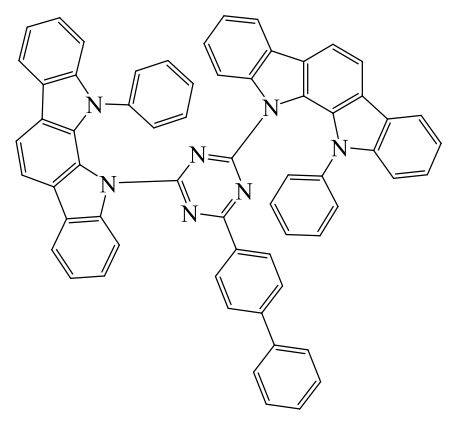

PIC-TRZ

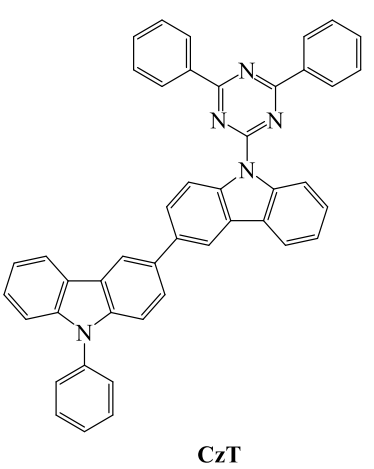

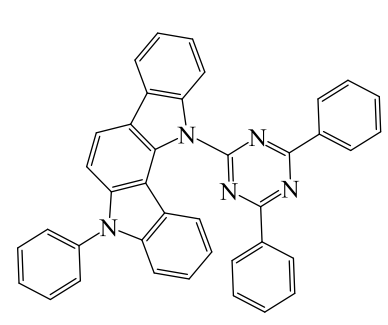

PIC-TRZ2<smiles></smiles>

PhCzTAZ

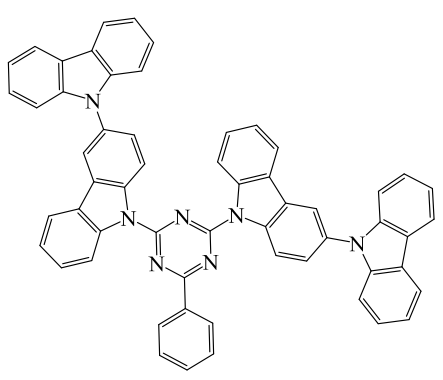

CC2TA

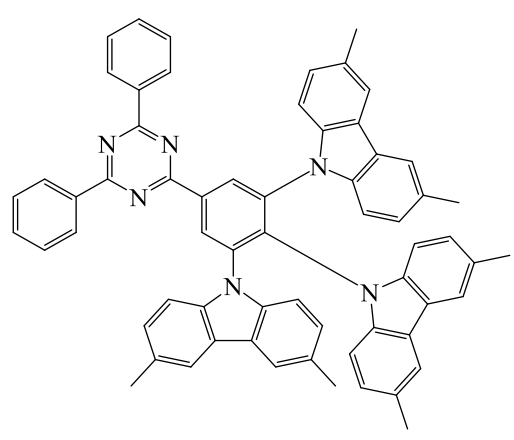<smiles>Cc1ccc2c(c1)c1cc(C)ccc1n2-c1cc(-n2c3ccccc3c3ccccc32)cc(-n2c3ccccc3c3ccccc32)c1-n1nc(-c2ccccc2)nc1-c1ccccc1</smiles>

Figure 1. Molecular structures of triazine acceptors with carbazole donor moieties.

The study of the 9-(4-(4,6-diphenyl-1,3,5-triazin-2-yl)phenyl)-N3,N3,N6,N6-tetraphenyl-9Hcarbazole-3,6-diamine (DACT-II) molecule (Figure 2) showed an interesting photoluminescent quantum yield of $100 \%$, which matched the theoretical IQE of $100 \%$. The energy difference between the singlet and triplet states was $0.009 \mathrm{eV}$. An energy gap near zero supported a large oscillator strength and an effective RISC process. The bulky molecular structure had favorable thermal properties, and the decomposition temperature was $484{ }^{\circ} \mathrm{C}$ at $5 \%$ weight reduction. The symmetric diphenylaminocarbazole donor in this molecule played an important role in the device efficiencies. An OLED device was fabricated with a 100 nm thick 4,4'-Cyclohexylidenebis[N,N-bis(4-methylphenyl)benzenamine] (TAPC) hole-transporting layer and was doped with CBP host material. An EQE of 29.6\% was recorded without any outcoupling techniques. At the same time, the device exhibited low power consumption, even at high thickness [84].

Dibenzofuran-carbazole-donor-based 9-(4-(4,6-diphenyl-1,3,5-triazin-2-yl)dibenzo[b,d]furan-3-yl)9'-phenyl-9H,9'H-3,3'-bicarbazole (BCzTrzDBF), 9'-(4-(4,6-diphenyl-1,3,5-triazin-2-yl)dibenzo[b,d] 
furan-3-yl)-9,9'-diphenyl-9H, $9^{\prime} \mathrm{H}, 9^{\prime \prime} \mathrm{H}-3,3^{\prime}: 6^{\prime}, 3^{\prime \prime}$-tercarbazole (TCzTrzDBF), and 12-(4-(4,6-diphenyl1,3,5-triazin-2-yl)dibenzo[b,d]furan-3-yl)-5-phenyl-5,12-dihydroindolo[3,2a]carbazole (IDCzTrzDBF) were synthesized and used for green TADF emitters (Figure 2). A dibenzofuran unit was used as the backbone between the carbazole donor and the triazine acceptor, and a HOMO-LUMO distribution confirmed the linker unit. All three molecules exhibited PLQYs over $80 \%$. The delayed time was recorded as 5.4, 4.4, and $2.8 \mu \mathrm{s}$ for BCzTrzDBF, TCzTrzDBF, and IDCzTrzDBF, respectively. The reverse intersystem crossing rate constant of IDCzTrzDBF was high due to the large angle between the indolocarbazole donor and the dibenzofuran linker. TCzTrzDBF exhibited the highest horizontal dipole alignment ratio relative to the substrate of 0.79 , which helped to bring a higher EQE of $23.5 \%$ compared with BCzTrzDBF $(20.1 \%)$ and IDCzTrzDBF (12.2\%). Moreover, the three-carbazole-unit-based TCzTrzDBF enhanced the current and power efficiencies $(74.8 \mathrm{~cd} / \mathrm{A}$ and $44.7 \mathrm{~lm} / \mathrm{W}$, respectively) compared with the two-carbazole-unit-based BCzTrzDBF $(59.6 \mathrm{~cd} / \mathrm{A}, 35.1 \mathrm{~lm} / \mathrm{W})$. Further studies were carried out by Jung et al. by changing the donor and acceptor positions with a dibenzofuran linker unit (Figure 2). 9-(4-(4,6diphenyl-1,3,5-triazin-2-yl)dibenzo[b,d]furan-3-yl)-9' -phenyl-9H, $9^{\prime} \mathrm{H}-3,3^{\prime}$-bicarbazole $\quad$ (2Cz3Trz) and 9-(2-(4,6-diphenyl-1,3,5-triazin-2-yl)dibenzo[b,d]furan-3-yl)-9' -phenyl-9H, $9^{\prime} \mathrm{H}-3,3^{\prime}$ - bicarbazole (3Cz2Trz) showed low PLQYs and device efficiencies compared with TCzTrzDBF. Changing the acceptor attached position and reducing the amount of carbazole did not reveal any interesting efficiency enhancements. However, a dibenzofuran linker can suppress the nonradiative mechanism when compared with the presence of a phenyl linker moiety [90,91].

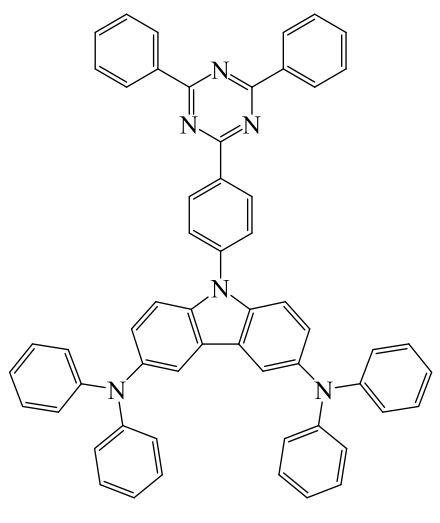

DACT-II

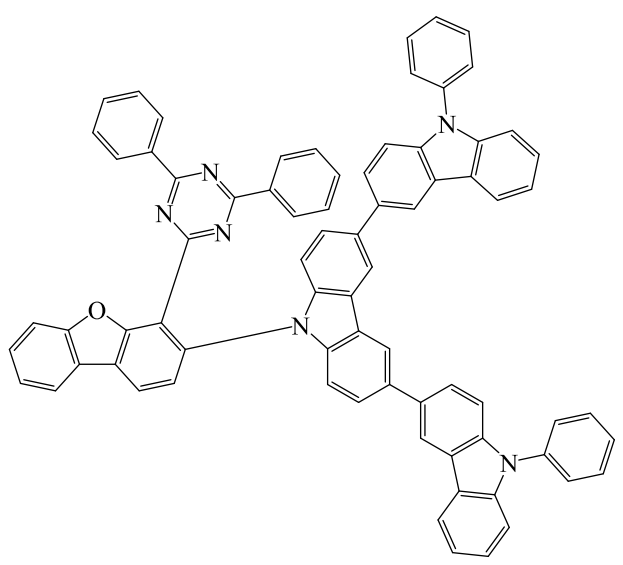

TCzTrzDBF

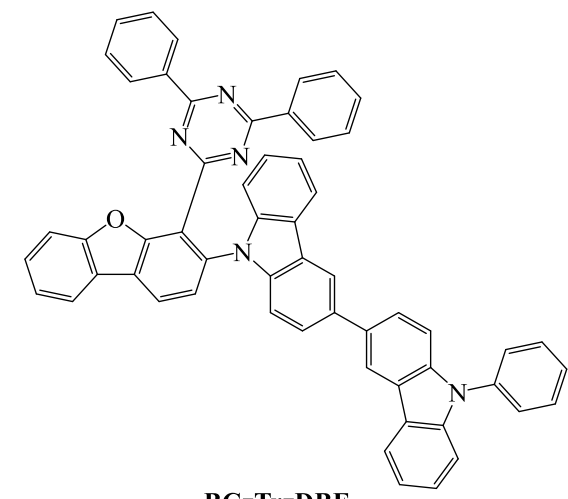

BCzTrzDBF

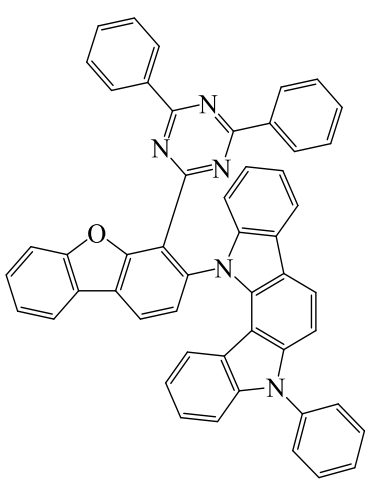

IDCzTrzDBF

Figure 2. Cont. 


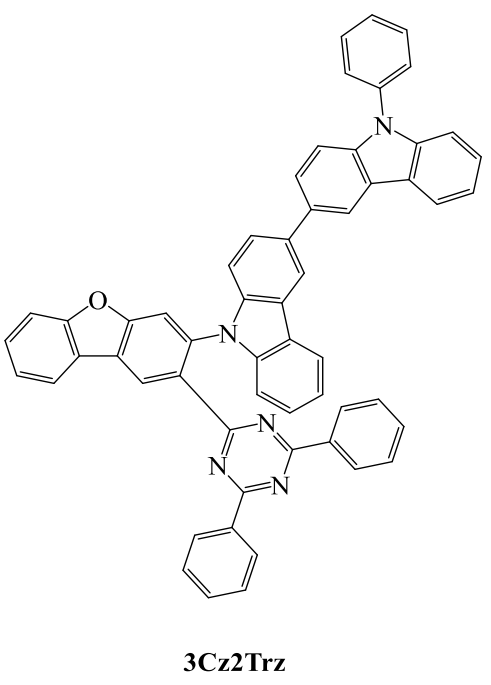

Figure 2. Molecular structures of triazine acceptors with carbazole, along with other donor derivatives.

Carbazole and its derivatives with a triazine acceptor were the subject of an interesting study on device performances. The monosubstituted indolocarbazole donor moiety PIC-TRZ2 showed a well-separated frontier molecular orbital distribution compared with disubstituted indolocarbazole PIC-TRZ2, which helped to increase the EQE from 5.3\% to 12.5\%. However, these two molecules did not have any phenyl linker or spacer molecule between the donor and the acceptor. A bicarbazole donor and triazine acceptor without any phenyl linker showed the opposite performance, and disubstituted CC2TA revealed better performances (11\%) than the monosubstituted CzT molecule (6\%). Symmetrical molecules of DPA-TRZ and DACT-II with a phenyl linker unit exhibited better device properties. Carbazole with diphenyl amine at the third and sixth positions (DACT-II) enhanced the device quantum efficiency up to $29.6 \%$, while diphenyl amine, at the third and sixth positions of diphenylamine (DPA-TRZ), showed a low efficiency of $13.8 \%$. So, carbazole with a diphenylamine donor at the third and sixth positions resulted in a more interesting effect with the triazine acceptor than a similar molecular design with diphenylamine donor derivatives. A IDCzTrzDBF molecule was constructed with a furan linker between an indolocarbazole donor and a triazine acceptor, but this linker moiety and substituted position did not have a successful effect on the external quantum efficiency. A furan linker moiety attached to a symmetrical donor of carbazole with third- and sixth-position-substituted phenyl carbazole (TCzTrzDBF) showed better performance. When the number of carbazole donor moieties was increased and attached to the phenyl group at meta and para positions (TmCzTrz), the result was an EQE over 25\%. Overall, a carbazole donor containing a symmetrical structure, along with free rotating substitutions at the third and sixth positions, and a number of carbazole donors attached through meta and para substitution further helped to achieve high EQEs for green TADF emitters compared with carbazole-based rigid donor derivatives of indolocarbazole.

The indeno-acridine strong-donor-based 5-(4-(4,6-diphenyl-1,3,5-triazin-2-yl)phenyl)-7,7,13,13tetramethyl-7,13-dihydro-5H-indeno[1,2-b]acridine (TrzIAc) molecule (Figure 3) was reported to have a PLQY of $97 \%$. Delayed fluorescence was observed at $1.6 \mu \mathrm{s}$, with a singlet-triplet energy difference of $0.06 \mathrm{eV}$. The rigid donor molecule enhanced the thermal stabilities of TrzIAc. OLED device performances were noticed when $20 \mathrm{wt} \%$ was doped with mixed hosts of mCP and TPBI. An EQE of $20.9 \%$ was recorded, which was higher than that of acridine-donor-based $\operatorname{TrzAc}(17.7 \%)$. The indeno-acridine donor moiety not only enhanced the thermal stability but also improved device efficiencies with green color emission (511 nm) [61].

Kang et al. reported two TADF emitters with rigid donors of benzofuran-acridine (13-(4(4,6-diphenyl-1,3,5-triazin-2-yl)phenyl)-5,5-dimethyl-5,13-dihydrobenzofuro[3,2-c]acridine, BFAcTRZ) and benzothiophene-acridine (13-(4-(4,6-diphenyl-1,3,5-triazin-2-yl)phenyl)-5,5-dimethyl-5,13- 
dihydrobenzo[4,5]thieno[3,2-c]acridine, BTAcTRZ) with a triazine acceptor (Figure 3). The PLQY of BTAcTRZ was as high as $100 \%$, and the energy difference between singlet and triplet states was as small as $0.02 \mathrm{eV}$, with a delayed fluorescence of $9.3 \mu \mathrm{s}$. The constant of reverse intersystem crossing was higher in benzothiophene-based BTAcTRZ. The EQEs of BFAcTRZ (20.4\%) and BTAcTRZ $(21.8 \%)$ were higher than $20 \%$, and BTAcTRZ exhibited better efficiencies than that of the indeno-acridine-based TrzIAc molecule. The BTAcTRZ molecule showed a red-shifted electroluminescent emission of $526 \mathrm{~nm}$ due to its donor moiety $[61,92]$.

Rigid donor moieties of indeno-acridine-, dibenzofuro-acridine-, and benzothieno-acridine-based TrzIAc, BFAcTrz, and BTAcTrz revealed better EQEs, which were higher than those of indolocarbazole-based green TADF emitters.<smiles>CC1(C)c2ccccc2-c2cc3c(cc21)N(c1ccc(-c2nc(-c4ccccc4)nc(-c4ccccc4)n2)cc1)c1ccccc1C3(C)C</smiles>

TrzIAc<smiles>CC1(C)c2ccccc2N(c2ccc(-c3nc(-c4ccccc4)nc(-c4ccccc4)n3)cc2)c2c1oc1ccccc21</smiles>

BFAcTrz<smiles>CC1(C)c2ccccc2N(c2ccc(-c3nc(-c4ccccc4)nc(-c4ccccc4)n3)cc2)c2c1sc1ccccc21</smiles>

\section{BTAcTrz}

Figure 3. Molecular structures of triazine acceptors with acridine-based rigid donor moieties.

The 10-(4-(4,6-diphenyl-1,3,5-triazin-2-yl)phenyl)-10H-phenoxazine (PXZ-TRZ) material with a phenoxazine donor (Figure 4) showed a dihedral angle between donor and acceptor of $74.8^{\circ}$, which made an effective separation of HOMO and LUMO. There was a small energy gap between the singlet and triplet states of $0.07 \mathrm{eV}$, which was obtained through a phenyl linker between the donor and the acceptor. A PLQY of $65.7 \%$ resulted in an EQE of $12.5 \%$. There was a short delayed fluorescence at $0.68 \mu \mathrm{s}$, and the maxima of the electroluminescent spectra was at $529 \mathrm{~nm}$. Later, di- and trisubstituted phenoxazine donors with a triazine acceptor moiety were reported. 2,4,6-Tris(4-(10H-phenoxazin-10-yl)phenyl)-1,3,5-triazine (Tri-PXZ-TRZ) revealed an EQE of 13.3\%, which was higher than that of the single-substituted donor molecule. Moreover, the trisubstituted material showed red-shifted emission, and the PLQY was 58\% [93,94]. 
Table 1. Photophysical properties of triazine-based green thermally activated delayed fluorescence (TADF) emitters.

\begin{tabular}{|c|c|c|c|c|c|c|c|}
\hline TADF Emitter & $\begin{array}{c}\text { HOMO } \\
(\mathrm{eV})\end{array}$ & $\begin{array}{c}\text { LUMO } \\
(\mathrm{eV})\end{array}$ & PL (nm) & $\Delta \mathrm{E}_{\mathrm{ST}}(\mathrm{eV})$ & $\Phi_{\mathrm{PL}}(\%)$ & $\tau_{d}(\mu s)$ & Reference \\
\hline PIC-TRZ & - & - & 500 & 0.11 & 39 & 230 & [86] \\
\hline PXZ-TRZ & 5.5 & 3.1 & 540 & 0.07 & 65.7 & 0.68 & [89] \\
\hline CC2TA & 5.9 & 2.6 & $513^{a}$ & 0.05 & 62 & 22 & [87] \\
\hline PIC-TRZ2 & - & - & - & 0.02 & 45 & 2.7 & [86] \\
\hline Bis-PXZ-TRZ & 5.7 & 3.4 & $560^{a}$ & $0.054^{\mathrm{b}}$ & 64 & $1.33^{\mathrm{a}}$ & [90] \\
\hline Tri-PXZ-TRZ & 5.7 & 3.4 & $568^{a}$ & $0.065^{b}$ & 58 & $1.10^{\mathrm{a}}$ & [90] \\
\hline $\mathrm{CzT}$ & - & - & 502 & 0.07 & 39.7 & $42.6^{\mathrm{a}}$ & [88] \\
\hline PTZ-TRZ & 5.5 & 3.0 & 420,520 & $0.18^{\mathrm{b}}$ & 65.8 & $0.52^{a}$ & [89] \\
\hline DMAC-TRZ & 5.3 & 2.78 & 510 & 0.05 & 83 & 3.6 & [82] \\
\hline DACT-II & 5.5 & 3.2 & 520 & 0.009 & 100 & - & [84] \\
\hline DPA-TRZ & - & - & 540 & 0.11 & 100 & 160 & [91] \\
\hline TrzIAc & 5.75 & 3.34 & 519 & 0.06 & $97^{\mathrm{a}}$ & 1.6 & [61] \\
\hline 3ACR-TRZ & - & - & 504 & 0.015 & $98^{\mathrm{a}}$ & 6.7 & [93] \\
\hline BCzTrzDBF & 5.85 & 3.34 & - & 0.06 & 82.4 & 5.4 & [95] \\
\hline TCzTrzDBF & 5.87 & 3.43 & - & 0.01 & 86.3 & 4.4 & [95] \\
\hline IDCzTrzDBF & 5.88 & 3.34 & - & 0.05 & 85.4 & 2.8 & [95] \\
\hline BFAcTrz & 5.84 & 3.23 & - & 0.11 & 92.3 & 14.2 & [94] \\
\hline BTAcTrz & 5.8 & 3.24 & - & 0.02 & 100 & 9.3 & [94] \\
\hline TmCzTrz & $5.19^{b}$ & $2.11^{b}$ & - & 0.07 & 100 & 13.3 & [92] \\
\hline DCzmCzTrz & $5.26^{\mathrm{b}}$ & $2.15^{b}$ & - & 0.20 & 98 & 9.7 & [92] \\
\hline TRZ-DDMAc & 5.70 & 2.89 & 529 & 0.03 & 52.7 & 10.32 & [83] \\
\hline TRZ-DDPAc & 5.72 & 2.87 & 511 & 0.05 & 79.7 & 10.37 & [83] \\
\hline 2Cz3Trz & 5.78 & 3.32 & - & 0.06 & 74.2 & 4.80 & [96] \\
\hline $3 \mathrm{Cz} 2 \mathrm{Trz}$ & 5.77 & 3.20 & - & 0.05 & 69.7 & 2.84 & [96] \\
\hline
\end{tabular}

Tanaka et al. developed the phenothiazine-donor-and-triazine-acceptor-based 10-(4-(4,6-diphenyl1,3,5-triazin-2-yl)phenyl)-10H-phenothiazine (PTZ-TRZ) TADF emitter (Figure 5), which had a phenyl linker between the donor and the acceptor. It was noticed that PTZ-TRZ exhibited dual ICT fluorescence in solid and solution states with a small singlet-triplet energy difference. PTZ-TRZ revealed quasi-equatorial conformation and had a lower dihedral angle between donor and acceptor compared with phenoxazine-based PXZ-TRZ. Two PL emissions were observed at 409 and $562 \mathrm{~nm}$, which were assigned to the quasi-axial and quasi-equatorial conformers, respectively. This OLED device, at a low concentration of $2 \mathrm{wt} \%$ PTZ-TRZ, showed an EQE of $10.8 \%$ and a PLQY of $65.8 \%[60,93]$.

Shizu et al. reported another molecule (N1-(4-(4,6-diphenyl-1,3,5-triazin-2-yl)phenyl)-N1-(4(diphenylamino)phenyl)-N4,N4-diphenylbenzene-1,4-diamine, DPA-TRZ) (Figure 5) with a 100\% PLQY. When DPA-TRZ was doped with host material, nonradiative decay was suppressed, which helped the effective reverse intersystem crossing mechanism. A long delayed component of $160 \mu \mathrm{s}$ was observed, which confirmed the presence of TADF characteristics. An EQE of 13.8\% was recorded at a current density of $0.01 \mathrm{~mA} / \mathrm{Cm}^{-2}$. The device efficiencies were notably better than those of phenothiazine-based PTZ-TRZ and phenoxazine-based PXZ-TRZ devices. The electroluminescent (EL) emission was notices at $548 \mathrm{~nm}$, which showed little red shifting due to its long conjugation donor molecule $[60,93,95]$. 
<smiles>c1ccc(-c2nc(-c3ccccc3)nc(-c3ccc(N4c5ccccc5Oc5ccccc54)cc3)n2)cc1</smiles>

PXZ-TRZ<smiles>c1ccc(-c2nc(-c3ccc(N4c5ccccc5Oc5ccccc54)cc3)nc(-c3ccc(N4c5ccccc5Oc5ccccc54)cc3)n2)cc1</smiles>

bis-PXZ-TRZ<smiles></smiles>

Figure 4. Molecular structures of triazine acceptors with phenoxazine donor moieties.<smiles>c1ccc(-c2nc(-c3ccccc3)nc(-c3ccc(N4c5ccccc5Sc5ccccc54)cc3)n2)cc1</smiles>

PTZ-TRZ<smiles>c1ccc(-c2nc(-c3ccccc3)nc(-c3ccc(N(c4ccc(N(c5ccccc5)c5ccccc5)cc4)c4ccc(N(c5ccccc5)c5ccccc5)cc4)cc3)n2)cc1</smiles>

DPA-TRZ

Figure 5. Molecular structures of triazine acceptors with phenothiazine and diphenylamine donor moieties.

Tsai et al. introduced 10-(4-(4,6-diphenyl-1,3,5-triazin-2-yl)phenyl)-9,9-dimethyl-9,10-dihydroacridine (DMAC-TRZ) (Figure 6) with a dimethyl acridine donor, which showed high PLQYs of $83 \%$ and $90 \%$ for neat and doped films, respectively. The geometrical optimization showed that DMAC-TRZ had a large dihedral angle of $88^{\circ}$ between the acridine donor and the triazine acceptor. DMAC-TRZ exhibited more stable thermal properties than those of phenoxazine-based PXZ-TRZ. Delayed fluorescence was observed at $3.6 \mu$ s in the neat film state, while it was $1.9 \mu$ s in the doped film state. The high PLQY 
in neat and doped film states suggests that two different devices with doped and undoped TADF emitters could be fabricated. The doped device with mCPCN host material showed current, power, and external quantum efficiencies of $66.8 \mathrm{~cd} / \mathrm{A}, 65.6 \mathrm{~lm} / \mathrm{W}$, and $26.5 \%$, respectively. The undoped device had current and external quantum efficiencies of $61.1 \mathrm{~cd} / \mathrm{A}$ and $20 \%$. Such high efficiencies for an undoped device were explained by the effective mechanism of RISC [82,93].

Further development of acridine-donor-based 2,4,6-tris(4-(9,9-dimethylacridin-10(9H)-yl)phenyl)1,3,5-triazine (3ACR-TRZ) TADF emitters (Figure 6) for solution-processable OLEDs was reported by Wada et al. 3ACR-TRZ showed a high PLQY of 98\%, which was higher than that of DMAC-TRZ. The increased number of acridine donor molecules helped to reduce the energy gap between the singlet and triplet states to $0.015 \mathrm{eV}$, and a slightly longer delayed fluorescence was recorded at $6.7 \mu \mathrm{s}$. The OLED device was fabricated with a $16 \mathrm{wt} \%$ emitter doped with CBP host material. The EQE was $18.6 \%$, which was higher than that of the phenoxazine-based three site molecule Tri-PXZ-TRZ. The dimethyl acridine donor provided good properties as well as easy solution processability [82,94,96].

Recently, our group reported two TADF emitters based on an acridine-triazine molecular backbone. Two different acridine donors, such as dimethyl acridine (10,10' -(5-(4,6-diphenyl-1,3,5-triazin2-yl)-1,3-phenylene)bis(9,9-dimethyl-9,10-dihydroacridine), TRZ-DDMAc) and diphenyl acridine (10,10'-(5-(4,6-diphenyl-1,3,5-triazin-2-yl)-1,3-phenylene)bis(9,9-diphenyl-9,10-dihydroacridine), TRZDDPAc) were constructed (Figure 6) with a D-A-D structure and a phenyl linker between the donor and the acceptor. Interestingly, the diphenyl-acridine-donor-based molecule revealed a PLQY (79.7\%) higher than that of the dimethyl-acridine-based molecule. The calculation method showed that the nonradiative decay rate of the dimethyl acridine donor molecule was two times that of the diphenyl donor molecule. A device using TRZ-DDPAc doped with the polar host material DBFPO showed excellent efficiencies of $62.8 \mathrm{~cd} / \mathrm{A}, 56.3 \mathrm{~lm} / \mathrm{W}$, and $27.3 \%$ for current, power, and external quantum efficiencies, respectively [83].<smiles>CC1(C)c2ccccc2N(c2ccc(-c3nc(-c4ccccc4)nc(-c4ccccc4)n3)cc2)C2C=CC=CC21</smiles>

DMAC-TRZ<smiles>CC1(C)c2ccccc2N(c2cc(-c3nc(-c4ccccc4)nc(-c4ccccc4)n3)cc(N3c4ccccc4C(C)(C)c4ccccc43)c2)c2ccccc21</smiles>

TRZ-DDMAc<smiles>CC1(C)c2ccccc2N(c2ccc(-c3nc(-c4ccc(N5c6ccccc6C(C)(C)c6ccccc65)cc4)nc(-c4ccc(N5c6ccccc6C(C)(C)c6ccccc65)cc4)n3)cc2)c2ccccc21</smiles>

3ACR-TRZ

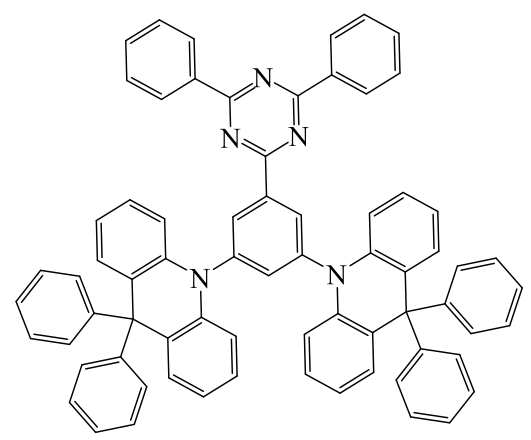

TRZ-DDPAc

Figure 6. Molecular structures of triazine acceptors with acridine donor moieties. 
Table 2. Organic light-emitting diodes (OLED) device evaluation performances of triazine-based green TADF emitters.

\begin{tabular}{|c|c|c|c|c|c|c|c|c|}
\hline TADF Emitter & Device Structure & EML (nm) & $\mathrm{EL}_{\max }(\mathrm{nm})$ & CIE Color & $\mathrm{CE}$ (cd/A) & PE $(\operatorname{lm} / \mathrm{W})$ & EQE (\%) & Reference \\
\hline PIC-TRZ & ITO/NPD/ $\alpha-\mathrm{mCP} / 6$ wt \% PIC-TRZ: mCP/BP4mPy/LiF/Al & 15 & 500 & - & - & - & 5.3 & [86] \\
\hline PXZ-TRZ & ITO/ $\alpha-\mathrm{NPD} / 6$ wt \% PXZ-TRZ: CBP/TPBi/LiF/Al & 15 & 529 & - & - & - & 12.5 & [89] \\
\hline CC2TA & $\begin{array}{l}\text { ITO/ } \alpha-\mathrm{NPD} / 6 \text { wt } \% \text { CC2TA: mCP/6 wt \% CC2TA: } \\
\text { DPEPO/DPEPO/TPBi/LiF/Al }\end{array}$ & 30 & 490 & - & - & - & 11.0 & [87] \\
\hline PIC-TRZ2 & $\begin{array}{l}\text { ITO/TAPC/6 wt \% PIC-TRZ2: } \\
\text { PYD2/DPEPO/TmPyPBi/LiF/Al }\end{array}$ & 20 & 505 & - & - & - & 14.0 & [86] \\
\hline Bis-PXZ-TRZ & ITO/ $\alpha-N P D / 6$ wt \% Bis-PXZ-TRZ: mCBP/TPBi/LiF/Al & 15 & 552 & - & - & - & 9.1 & [90] \\
\hline Tri-PXZ-TRZ & ITO/ $\alpha-N P D / 6$ wt \% Tri-PXZ-TRZ: mCBP/TPBi/LiF/Al & 15 & 553 & - & - & - & 13.3 & [90] \\
\hline CzT & $\begin{array}{l}\text { ITO/ } \alpha-\mathrm{NPD} / \mathrm{TCTA} / \mathrm{CzSi} / 3 \mathrm{wt} \% \mathrm{CzT} \text { : } \\
\text { DPEPO/DPEPO/TPBi/LiF/Al }\end{array}$ & 20 & 520 & $0.23,0.40$ & - & 9.7 & 6.0 & [88] \\
\hline PTZ-TRZ & ITO/ $\alpha-\mathrm{NPD} / 2$ wt \% PTZ-TRZ: mCBP/TPBi/LiF/Al & 15 & 532 & - & - & - & 10.8 & [89] \\
\hline DMAC-TRZ & $\begin{array}{c}\text { ITO/PEDOT: PSS/TAPC/mCP/8 wt \% DMAC-TRZ: } \\
\text { mCPCN/DPSS/3TPYMB/LiF/Al } \\
\text { (nondoped device): ITO/PEDOT: } \\
\text { PSS/TAPC/mCp/DMAC-TRZ/3TPYMB/LiF/Al }\end{array}$ & 20 & - & - & $\begin{array}{l}66.8 \\
61.1\end{array}$ & $\begin{array}{l}65.6 \\
45.7\end{array}$ & $\begin{array}{l}26.5 \\
20.0\end{array}$ & [82] \\
\hline DACT-II & ITO/TAPC/9 wt \% DACT-II: CBP/BAlq/Liq/Al & 40 & - & - & - & - & 29.6 & [84] \\
\hline DPA-TRZ & ITO/ $\alpha-\mathrm{NPD} / 6$ wt \% DPA-TRZ: mCBP/TPBi/LiF/Al & 15 & 548 & - & - & - & 13.8 & [91] \\
\hline TrzIAc & $20 \mathrm{wt} \%$ TrzIAc: $\mathrm{mCP}$ and TPBI & 25 & 511 & $0.33,0.57$ & - & - & 20.9 & [61] \\
\hline 3ACR-TRZ & $\begin{array}{l}\text { ITO/PEDOT: PSS/16 wt \% 3ACR-TRZ: } \\
\text { CBP/BmPyPhB/Liq/Al }\end{array}$ & 55 & 520 & - & - & - & 18.6 & [93] \\
\hline BCzTrzDBF & $\begin{array}{c}\text { ITO/DNTPD/BPBPA/PCzAc/5 wt \% BCzTrzDBF: } \\
\text { mCBPTrz/DBFTrz/ZADN/LiF/Al }\end{array}$ & 30 & 503 & $0.24,0.52$ & 59.6 & 35.1 & 20.1 & [95] \\
\hline TCzTrzDBF & $\begin{array}{c}\text { ITO/DNTPD/BPBPA/PCzAc/5 wt \% TCzTrzDBF: } \\
\text { mCBPTrz/DBFTrz/ZADN/LiF/Al }\end{array}$ & 30 & 511 & $0.27,0.57$ & 74.8 & 44.7 & 23.5 & [95] \\
\hline IDCzTrzDBF & $\begin{array}{c}\text { ITO/DNTPD/BPBPA/PCzAc/5 wt \% IDCzTrzDBF: } \\
\text { mCBPTrz/DBFTrz/ZADN/LiF/Al }\end{array}$ & 30 & 500 & $0.22,0.48$ & 33.6 & 19.3 & 12.2 & [95] \\
\hline BFAcTrz & $\begin{array}{c}\text { ITO/PEDOT: PSS/TAPC/mCP/30 wt \% BFAcTrz: } \\
\text { DPEPO/TSPOI/TPBi/LiF/Al }\end{array}$ & 25 & 506 & $0.25,0.51$ & 58.7 & 52.7 & 20.4 & [94] \\
\hline
\end{tabular}


Table 2. Cont

\begin{tabular}{|c|c|c|c|c|c|c|c|c|}
\hline TADF Emitter & Device Structure & EML (nm) & $\mathrm{EL}_{\max }(\mathrm{nm})$ & CIE Color & CE (cd/A) & $\mathrm{PE}(\mathrm{lm} / \mathrm{W})$ & EQE (\%) & Reference \\
\hline BTAcTrz & $\begin{array}{c}\text { ITO/PEDOT: PSS/TAPC/mCP/50 wt \% BTAcTrz: } \\
\text { DPEPO/TSPO1/TPBi/LiF/Al }\end{array}$ & 25 & 526 & $0.35,0.57$ & 68.9 & 58.5 & 21.8 & [94] \\
\hline TmCzTrz & $\begin{array}{c}\text { ITO/PEDOT: PSS/TAPC/mCP/30 wt \% TmCzTrz: } \\
\text { DPEPO/TSPO1/TPBI/LiF/Al }\end{array}$ & 25 & 500 & $0.25,0.50$ & 18.6 & 52.1 & 25.5 & [92] \\
\hline DCzmCzTrz & $\begin{array}{c}\text { ITO/PEDOT: PSS/TAPC/mCP/20 wt \% DCzmCzTrz: } \\
\text { DPEPO/TSPO1/TPBI/LiF/Al }\end{array}$ & 25 & 496 & $0.23,0.46$ & 16.8 & 42.4 & 21.3 & [92] \\
\hline TRZ-DDPAc & $\begin{array}{c}\text { ITO/HATCN/TAPC/DCDPA/30 wt \% TRZ-DDPAc: } \\
\text { DBFPO/TPBi/LiF/Al }\end{array}$ & 25 & 509 & $0.25,0.52$ & 62.8 & 56.3 & 27.3 & [83] \\
\hline TRZ-DDMAc & $\begin{array}{l}\text { ITO/HATCN/TAPC/DCDPA/20 wt \% TRZ-DDMAc: } \\
\text { PPBI/TPBi/LiF/Al }\end{array}$ & 25 & 511 & $0.26,0.54$ & 43.2 & 33.7 & 17.6 & [83] \\
\hline $2 \mathrm{Cz} 3 \operatorname{Trz}$ & $\begin{array}{c}\text { ITO/DNTPD/BPBPA/PCZAC/10 wt \% 2Cz3Trz: } \\
\text { CzTrz/CzTrz/ZADN/LiF/Al }\end{array}$ & 30 & 521 & $0.30,0.56$ & 55.8 & 28.3 & 17.9 & [96] \\
\hline $3 \operatorname{Cz} 2 \operatorname{Trz}$ & $\begin{array}{c}\text { ITO/DNTPD/BPBPA/PCZAC/10 wt \% 3Cz2Trz: } \\
\text { CzTrz/CzTrz/ZADN/LiF/Al }\end{array}$ & 30 & 512 & $0.26,0.50$ & 42.9 & 21.8 & 15.0 & [96] \\
\hline
\end{tabular}


Regarding the device performances of triazine-based green TADF emitters, DACT-II-, TRZ-DDPAc-, DMAC-TRZ-, and TmCzTrz-based devices exhibited good EQEs of 29.6\%, 27.3\%, 26.5\%, and $25.5 \%$, respectively. The DACT-II molecular design had a carbazole donor with symmetrically attached diphenylamine units, while the TmCzTrz molecule was constructed with three carbazole units at the meta and para positions of the phenyl linker. TRZ-DDPAc had two diphenyl acridine moieties at the meta positions of the phenyl linker group. The molecular design containing only donors of phenoxazine and phenothiazine did not show any impact on efficiency enhancement. Acridine derivatives had prominent effects on quantum efficiencies. The number of donor moieties with symmetrical attachments with the linker phenyl group enhanced the device properties.

Many donor derivatives were incorporated with triazine acceptors to design various green TADF emitters. The strong donor moieties of acridine, phenothiazine, diphenylamine, and phenoxazine and the weak donor moieties of carbazole, benzofurocarbazole, and benzothioenocarbazole were employed, showing suitable attachment to acceptor and linker units. We noticed that strong-donor-based PXZ-TRZ, PTZ-TRZ, Bis-PXZ-TRZ, Tris-PXZ-TRZ, and DPA-TRZ showed red-shifted emissions of 529, 532, 552, 553, and $548 \mathrm{~nm}$, respectively. The carbazole-donor-based CC2TA, PIC-TRZ, PIC-TRZ2, DCzmCzTrz, and TmCzTrz showed blue-shifted emissions of 490, 500, 505, 496, and $500 \mathrm{~nm}$, respectively. So, future works should consider elucidating which type of donor moiety is suitable for designing green TADF emitters with color purity emission.

Moreover, the selection of host materials, adjacent layers, and doping concentrations is important to ensure the effectiveness of the device. Among the above-reported triazine-based green TADF emitters, $20 \mathrm{wt} \%$ doped emitters of TrzIAc and DCzmCzTrz showed EQEs of 20.9\% and 21.3\%, respectively, and an emission layer thickness of $25 \mathrm{~nm}$. The $30 \mathrm{wt} \%$ doped BFAcTrz, TmCzTrz, and TRZ-DDPAc exhibited quantum efficiencies of $20.4 \%, 25.5 \%$, and $27.3 \%$, respectively, and had the same emission layer thickness of $25 \mathrm{~nm}$. A DACT-II-based device showed better device properties at a low doping concentration of $6 \%$, but the thickness of the emission layer was reported to be $40 \mathrm{~nm}$, and we believe that the greater thickness of the host material (CBP) supported an effective energy flow to achieve an EQE of 29.6\%. DMAC-TRZ showed good device characteristics (EQE of 26.5\%) and employed an $8 \%$ doping $(20 \mathrm{~nm})$ concentration and hole-blocking layer (DPSS). The acridine-based 3ACR-TRZ was $16 \mathrm{wt} \%$ doped with CBP as the host material, and the emission layer thickness was as high as $55 \mathrm{~nm}$, but the device could not reach an EQE over 19\%. So, for device optimization, using various doping concentrations and host materials is crucial to obtain an effective device. Host materials play a major role in device performance as they are responsible for supplying energy to the emission layer. At the same time, host materials control the charge recombination of collected electrons and holes from the cathode and anode, respectively. The choice of host material depends on the triplet energy of the dopant material, and high triplet energy host materials dope with dopant to establish an effective device.

\section{Conclusions}

Triazine-acceptor-based green TADF emitters with suitable donor derivatives and host materials have shown great performance in terms of device efficiency. The EQEs were over $29 \%$, which were higher than those of any red TADF emitters. Still, many improvements are needed in the molecular design to achieve a high efficiency. Host materials play a major role in device efficiency by supporting effective energy transfer to the dopant. Moreover, a proper doping concentration also enhances device performance. Triazine has exhibited good withdrawing characteristics and a suitable donor moiety connecting the appropriate position, which should result in a highly efficient and stable molecular design for green TADF emitters.

Author Contributions: Conceptualization, R.B.; Writing original draft, R.B.; Methodology, R.B.; Writing-Review \& Editing, R.B.; Supervision, K.Y.C. 
Funding: This research received no external funding.

Acknowledgments: This study was supported by Wonkwang University (2018).

Conflicts of Interest: The authors declare no conflict of interest.

\section{References}

1. Prachumrak, N.; Pojanasopa, S.; Namuangruk, S.; Kaewin, T.; Jungsuttiwong, S.; Sudyoadsuk, T.; Promarak, V. Novel bis[5-(fluoren-2-yl)thiophen-2-yl]benzothiadiazole end-capped with carbazole dendrons as highly efficient solution-processed nondoped red emitters for organic light-emitting diodes. ACS Appl. Mater. Interfaces 2013, 5, 8694-8703. [CrossRef] [PubMed]

2. Park, I.S.; Komiyama, H.; Yasuda, T. Pyrimidine-based twisted donor-acceptor delayed fluorescence molecules: A new universal platform for highly efficient blue electroluminescence. Chem. Sci. 2017, 8, 953-960. [CrossRef] [PubMed]

3. Lee, S.Y.; Adachi, C.; Yasuda, T. High-efficiency blue organic light-emitting diodes based on thermally activated delayed fluorescence from phenoxaphosphine and phenoxathiin derivatives. Adv. Mater. 2016, 28, 4626-4631. [CrossRef] [PubMed]

4. Cha, J.-R.; Lee, C.W.; Lee, J.Y.; Gong, M.-S. Design of ortho-linkage carbazole-triazine structure for high-efficiency blue thermally activated delayed fluorescent emitters. Dyes Pigments 2016, 134, 562-568. [CrossRef]

5. Sun, K.; Sun, Y.; Jiang, W.; Huang, S.; Tian, W.; Sun, Y. Highly efficient and color tunable thermally activated delayed fluorescent emitters and their applications for the solution-processed oleds. Dyes Pigments 2017, 139, 326-333. [CrossRef]

6. Kim, K.-S.; Jeong, S.; Kim, C.; Kwon, Y.; Choi, B.-D.; Han, Y.S. Synthesis and electro-optical properties of carbazole derivatives with high band gap energy. Thin Solid Films 2009, 518, 284-289. [CrossRef]

7. Takahashi, T.; Shizu, K.; Yasuda, T.; Togashi, K.; Adachi, C. Donor-acceptor-structured 1,4-diazatriphenylene derivatives exhibiting thermally activated delayed fluorescence: Design and synthesis, photophysical properties and oled characteristics. Sci. Technol. Adv. Mater. 2014, 15, 034202. [CrossRef]

8. Liu, M.; Seino, Y.; Chen, D.; Inomata, S.; Su, S.-J.; Sasabe, H.; Kido, J. Blue thermally activated delayed fluorescence materials based on bis(phenylsulfonyl)benzene derivatives. Chem. Commun. 2015, 51, 16353-16356. [CrossRef]

9. Braveenth, R.; Bae, I.-J.; Wang, Y.; Kim, S.H.; Kim, M.; Chai, K.Y. Acridine-triphenylamine based hole-transporting and hole-injecting material for highly efficient phosphorescent-based organic light emitting diodes. Appl. Sci. 2018, 8, 1168. [CrossRef]

10. Usluer, O.; Demic, S.; Egbe, D.A.M.; Birckner, E.; Tozlu, C.; Pivrikas, A.; Ramil, A.M.; Sariciftci, N.S. Fluorene-carbazole dendrimers: Synthesis, thermal, photophysical and electroluminescent device properties. Adv. Funct. Mater. 2010, 20, 4152-4161. [CrossRef]

11. Huh, D.H.; Kim, G.W.; Kim, G.H.; Kulshreshtha, C.; Kwon, J.H. High hole mobility hole transport material for organic light-emitting devices. Synth. Met. 2013, 180, 79-84. [CrossRef]

12. Braveenth, R.; Bae, H.W.; Ko, I.J.; Qiong, W.; Nguyen, Q.P.B.; Jayashantha, P.G.S.; Kwon, J.H.; Chai, K.Y. Thermally stable efficient hole transporting materials based on carbazole and triphenylamine core for red phosphorescent oleds. Org. Electron. 2017, 51, 463-470. [CrossRef]

13. Griniene, R.; Grazulevicius, J.V.; Tseng, K.Y.; Wang, W.B.; Jou, J.H.; Grigalevicius, S. Aryl substituted 9-(2,2-diphenylvinyl)carbazoles as efficient materials for hole transporting layers of oleds. Synth. Met. 2011, 161, 2466-2470. [CrossRef]

14. Zheng, Z.; Dong, Q.; Gou, L.; Su, J.-H.; Huang, J. Novel hole transport materials based on $\mathrm{n}, \mathrm{n}^{\prime}$-disubstituted-dihydrophenazine derivatives for electroluminescent diodes. J. Mater. Chem. C 2014, 2, 9858-9865. [CrossRef]

15. Shih, P.-I.; Chien, C.-H.; Chuang, C.-Y.; Shu, C.-F.; Yang, C.-H.; Chen, J.-H.; Chi, Y. Novel host material for highly efficient blue phosphorescent oleds. J. Mater. Chem. 2007, 17, 1692-1698. [CrossRef]

16. Lyu, Y.-Y.; Kwak, J.; Jeon, W.S.; Byun, Y.; Lee, H.S.; Kim, D.; Lee, C.; Char, K. Highly efficient red phosphorescent oleds based on non-conjugated silicon-cored spirobifluorene derivative doped with ir-complexes. Adv. Funct. Mater. 2009, 19, 420-427. [CrossRef] 
17. Tokito, S.; Iijima, T.; Suzuri, Y.; Kita, H.; Tsuzuki, T.; Sato, F. Confinement of triplet energy on phosphorescent molecules for highly-efficient organic blue-light-emitting devices. Appl. Phys. Lett. 2003, 83, 569-571. [CrossRef]

18. Ren, X.; Li, J.; Holmes, R.J.; Djurovich, P.I.; Forrest, S.R.; Thompson, M.E. Ultrahigh energy gap hosts in deep blue organic electrophosphorescent devices. Chem. Mater. 2004, 16, 4743-4747. [CrossRef]

19. Yeh, S.-J.; Wu, M.-F.; Chen, C.-T.; Song, Y.-H.; Chi, Y.; Ho, M.-H.; Hsu, S.-F.; Chen, C.H. New dopant and host materials for blue-light-emitting phosphorescent organic electroluminescent devices. Adv. Mater. 2005, 17, 285-289. [CrossRef]

20. Lee, S.Y.; Yasuda, T.; Yang, Y.S.; Zhang, Q.; Adachi, C. Luminous butterflies: Efficient exciton harvesting by benzophenone derivatives for full-color delayed fluorescence oleds. Angew. Chem. Int. Ed. 2014, 53, 6402-6406. [CrossRef]

21. Adachi, C.; Baldo, M.A.; Thompson, M.E.; Forrest, S.R. Nearly $100 \%$ internal phosphorescence efficiency in an organic light-emitting device. J. Appl. Phys. 2001, 90, 5048-5051. [CrossRef]

22. Xiao, L.; Su, S.-J.; Agata, Y.; Lan, H.; Kido, J. Nearly 100\% internal quantum efficiency in an organic blue-light electrophosphorescent device using a weak electron transporting material with a wide energy gap. Adv. Mater. 2009, 21, 1271-1274. [CrossRef]

23. Taneda, M.; Shizu, K.; Tanaka, H.; Adachi, C. High efficiency thermally activated delayed fluorescence based on 1,3,5-tris(4-(diphenylamino)phenyl)-2,4,6-tricyanobenzene. Chem. Commun. 2015, 51, 5028-5031. [CrossRef] [PubMed]

24. Park, I.S.; Lee, J.; Yasuda, T. High-performance blue organic light-emitting diodes with $20 \%$ external electroluminescence quantum efficiency based on pyrimidine-containing thermally activated delayed fluorescence emitters. J. Mater. Chem. C 2016, 4, 7911-7916. [CrossRef]

25. Kwon, D.Y.; Lee, G.H.; Kim, Y.S. Theoretical study of imidazole derivatives for blue thermally activated delayed fluorescence emitter. J. Nanosci. Nanotechnol. 2016, 16, 11014-11017. [CrossRef]

26. Yu, H.; Dai, X.; Yao, F.; Wei, X.; Cao, J.; Jhun, C. Efficient white phosphorescent organic light-emitting diodes using ultrathin emissive layers (. Sci. Rep. 2018, 8, 6068. [CrossRef] [PubMed]

27. Li, H.-Y.; Zhou, L.; Teng, M.-Y.; Xu, Q.-L.; Lin, C.; Zheng, Y.-X.; Zuo, J.-L.; Zhang, H.-J.; You, X.-Z. Highly efficient green phosphorescent oleds based on a novel iridium complex. J. Mater. Chem. C 2013, 1, 560-565. [CrossRef]

28. Thomas, S.T. Iridium(iii) complexes for oled application. In Iridium(iii) in Optoelectronic and Photonics Applications; John Wiley \& Sons: Hoboken, NJ, USA, 2017; pp. 205-274.

29. Yang, C.-H.; Mauro, M.; Polo, F.; Watanabe, S.; Muenster, I.; Fröhlich, R.; De Cola, L. Deep-blue-emitting heteroleptic iridium(iii) complexes suited for highly efficient phosphorescent oleds. Chem. Mater. 2012, 24, 3684-3695. [CrossRef]

30. Li, T.-Y.; Wu, J.; Wu, Z.-G.; Zheng, Y.-X.; Zuo, J.-L.; Pan, Y. Rational design of phosphorescent iridium(iii) complexes for emission color tunability and their applications in oleds. Coord. Chem. Rev. 2018, 374, 55-92. [CrossRef]

31. Cebrián, C.; Mauro, M. Recent advances in phosphorescent platinum complexes for organic light-emitting diodes. Beilstein J. Org. Chem. 2018, 14, 1459-1481. [CrossRef]

32. Li, K.; Ming Tong, G.S.; Wan, Q.; Cheng, G.; Tong, W.-Y.; Ang, W.-H.; Kwong, W.-L.; Che, C.-M. Highly phosphorescent platinum(ii) emitters: Photophysics, materials and biological applications. Chem. Sci. 2016, 7, 1653-1673. [CrossRef] [PubMed]

33. Peng, T.; Li, G.; Ye, K.; Wang, C.; Zhao, S.; Liu, Y.; Hou, Z.; Wang, Y. Highly efficient phosphorescent oleds with host-independent and concentration-insensitive properties based on a bipolar iridium complex. J. Mater. Chem. C 2013, 1, 2920-2926. [CrossRef]

34. Tao, Y.; Yang, C.; Qin, J. Organic host materials for phosphorescent organic light-emitting diodes. Chem. Soc. Rev. 2011, 40, 2943-2970. [CrossRef] [PubMed]

35. Cai, X.; Liu, R.; Shi, H.; Li, C.; Zhu, H. High efficiency green phosphorescent oleds using double-host materials. Dyes Pigments 2017, 143, 196-202. [CrossRef]

36. May, F.; Al-Helwi, M.; Baumeier, B.; Kowalsky, W.; Fuchs, E.; Lennartz, C.; Andrienko, D. Design rules for charge-transport efficient host materials for phosphorescent organic light-emitting diodes. J. Am. Chem. Soc. 2012, 134, 13818-13822. [CrossRef] [PubMed] 
37. Kwon, J.H.; Park, T.J.; Jeon, W.S.; Park, J.J. Bipolar Host Materials for Red and Green Phosphorescent Oled. In Proceedings of the Volume 6828, Light-Emitting Diode Materials and Devices II, Beijing, China, 11-15 November 2007. [CrossRef]

38. Zhan, G.; Liu, Z.; Bian, Z.; Huang, C. Recent advances in organic light-emitting diodes based on pure organic room temperature phosphorescence materials. Front. Chem. 2019, 7, 305. [CrossRef] [PubMed]

39. Chou, P.-T.; Chi, Y. Phosphorescent dyes for organic light-emitting diodes. Chem. Eur. J. 2007, 13, 380-395. [CrossRef]

40. Tung, Y.-L.; Lee, S.-W.; Chi, Y.; Chen, L.-S.; Shu, C.-F.; Wu, F.-I.; Carty, A.J.; Chou, P.-T.; Peng, S.-M.; Lee, G.-H. Organic light-emitting diodes based on charge-neutral ruii phosphorescent emitters. Adv. Mater. 2005, 17, 1059-1064. [CrossRef]

41. Wu, S.; Aonuma, M.; Zhang, Q.; Huang, S.; Nakagawa, T.; Kuwabara, K.; Adachi, C. High-efficiency deep-blue organic light-emitting diodes based on a thermally activated delayed fluorescence emitter. J. Mater. Chem. C 2014, 2, 421-424. [CrossRef]

42. Chaudhuri, D.; Sigmund, E.; Meyer, A.; Röck, L.; Klemm, P.; Lautenschlager, S.; Schmid, A.; Yost, S.R.; Van Voorhis, T.; Bange, S.; et al. Metal-free oled triplet emitters by side-stepping kasha's rule. Angew. Chem. Int. Ed. 2013, 52, 13449-13452. [CrossRef]

43. Chou, P.-T.; Chi, Y. Osmium- and ruthenium-based phosphorescent materials: Design, photophysics, and utilization in oled fabrication. Eur. J. Inorg. Chem. 2006, 2006, 3319-3332. [CrossRef]

44. Lin, C.-C.; Huang, M.-J.; Chiu, M.-J.; Huang, M.-P.; Chang, C.-C.; Liao, C.-Y.; Chiang, K.-M.; Shiau, Y.-J.; Chou, T.-Y.; Chu, L.-K.; et al. Molecular design of highly efficient thermally activated delayed fluorescence hosts for blue phosphorescent and fluorescent organic light-emitting diodes. Chem. Mater. 2017, 29, 1527-1537. [CrossRef]

45. Kim, M.; Jeon, S.K.; Hwang, S.-H.; Lee, J.Y. Stable blue thermally activated delayed fluorescent organic light-emitting diodes with three times longer lifetime than phosphorescent organic light-emitting diodes. Adv. Mater. 2015, 27, 2515-2520. [CrossRef] [PubMed]

46. Rajamalli, P.; Senthilkumar, N.; Gandeepan, P.; Ren-Wu, C.-Z.; Lin, H.-W.; Cheng, C.-H. A thermally activated delayed blue fluorescent emitter with reversible externally tunable emission. J. Mater. Chem. C 2016, 4, 900-904. [CrossRef]

47. Komatsu, R.; Sasabe, H.; Nakao, K.; Hayasaka, Y.; Ohsawa, T.; Kido, J. Unlocking the potential of pyrimidine conjugate emitters to realize high-performance organic light-emitting devices. Adv. Opt. Mater. 2017, 5, 1600675. [CrossRef]

48. Ihn, S.-G.; Lee, N.; Jeon, S.O.; Sim, M.; Kang, H.; Jung, Y.; Huh, D.H.; Son, Y.M.; Lee, S.Y.; Numata, M.; et al. An alternative host material for long-lifespan blue organic light-emitting diodes using thermally activated delayed fluorescence. Adv. Sci. 2017, 4, 1600502. [CrossRef] [PubMed]

49. Kim, J.U.; Reddy, S.S.; Cui, L.-S.; Nomura, H.; Hwang, S.; Kim, D.H.; Nakanotani, H.; Jin, S.H.; Adachi, C. Thermally activated delayed fluorescence of bis(9,9-dimethyl-9,10-dihydroacridine) dibenzo[b,d]thiophene 5,5-dioxide derivatives for organic light-emitting diodes. J. Lumin. 2017, 190, 485-491. [CrossRef]

50. Gómez-Bombarelli, R.; Aguilera-Iparraguirre, J.; Hirzel, T.D.; Duvenaud, D.; Maclaurin, D.; Blood-Forsythe, M.A.; Chae, H.S.; Einzinger, M.; Ha, D.-G.; Wu, T.; et al. Design of efficient molecular organic light-emitting diodes by a high-throughput virtual screening and experimental approach. Nat. Mater. 2016, 15, 1120-1127. [CrossRef]

51. Higuchi, T.; Nakanotani, H.; Adachi, C. High-efficiency white organic light-emitting diodes based on a blue thermally activated delayed fluorescent emitter combined with green and red fluorescent emitters. Adv. Mater. 2015, 27, 2019-2023. [CrossRef]

52. Huang, T.; Jiang, W.; Duan, L. Recent progress in solution processable tadf materials for organic light-emitting diodes. J. Mater. Chem. C 2018, 6, 5577-5596. [CrossRef]

53. Liang, X.; Tu, Z.-L.; Zheng, Y.-X. Thermally activated delayed fluorescence materials: Towards realization of high efficiency through strategic small molecular design. Chem. Eur. J. 2019, 25, 5623-5642. [CrossRef]

54. Bui, T.-T.; Goubard, F.; Ibrahim-Ouali, M.; Gigmes, D.; Dumur, F. Recent advances on organic blue thermally activated delayed fluorescence (tadf) emitters for organic light-emitting diodes (oleds). Beilstein J. Org. Chem. 2018, 14, 282-308. [CrossRef] [PubMed] 
55. Dias, F.B.; Penfold, T.J.; Monkman, A.P. Photophysics of thermally activated delayed fluorescence molecules. Methods Appl. Fluoresc. 2017, 5, 012001. [CrossRef] [PubMed]

56. Kitamoto, Y.; Namikawa, T.; Suzuki, T.; Miyata, Y.; Kita, H.; Sato, T.; Oi, S. Design and synthesis of efficient blue thermally activated delayed fluorescence molecules bearing triarylborane and 10,10-dimethyl-5,10-dihydrophenazasiline moieties. Tetrahedron Lett. 2016, 57, 4914-4917. [CrossRef]

57. Chen, X.-L.; Yu, R.; Zhang, Q.-K.; Zhou, L.-J.; Wu, X.-Y.; Zhang, Q.; Lu, C.-Z. Rational design of strongly blue-emitting cuprous complexes with thermally activated delayed fluorescence and application in solution-processed oleds. Chem. Mater. 2013, 25, 3910-3920. [CrossRef]

58. Gao, Y.; Su, T.; Zhao, L.; Geng, Y.; Wu, Y.; Zhang, M.; Su, Z.-M. How does a little difference in structure determine whether molecules have thermally activated delayed fluorescence characteristic or not? Org. Electron. 2017, 50, 70-76. [CrossRef]

59. Wang, H.; Xie, L.; Peng, Q.; Meng, L.; Wang, Y.; Yi, Y.; Wang, P. Novel thermally activated delayed fluorescence materials-thioxanthone derivatives and their applications for highly efficient oleds. Adv. Mater. 2014, 26, 5198-5204. [CrossRef]

60. Tanaka, H.; Shizu, K.; Nakanotani, H.; Adachi, C. Dual intramolecular charge-transfer fluorescence derived from a phenothiazine-triphenyltriazine derivative. J. Phys. Chem. C 2014, 118, 15985-15994. [CrossRef]

61. Seo, J.-A.; Gong, M.-S.; Song, W.; Lee, J.Y. Molecular orbital controlling donor moiety for high-efficiency thermally activated delayed fluorescent emitters. Chem. Asian J. 2016, 11, 868-873. [CrossRef]

62. Pan, K.-C.; Li, S.-W.; Ho, Y.-Y.; Shiu, Y.-J.; Tsai, W.-L.; Jiao, M.; Lee, W.-K.; Wu, C.-C.; Chung, C.-L.; Chatterjee, T.; et al. Efficient and tunable thermally activated delayed fluorescence emitters having orientation-adjustable cn-substituted pyridine and pyrimidine acceptor units. Adv. Funct. Mater. 2016, 26, 7560-7571. [CrossRef]

63. Kitamoto, Y.; Namikawa, T.; Suzuki, T.; Miyata, Y.; Kita, H.; Sato, T.; Oi, S. Dimesitylarylborane-based luminescent emitters exhibiting highly-efficient thermally activated delayed fluorescence for organic light-emitting diodes. Org. Electron. 2016, 34, 208-217. [CrossRef]

64. Liu, Y.; Li, C.; Ren, Z.; Yan, S.; Bryce, M.R. All-organic thermally activated delayed fluorescence materials for organic light-emitting diodes. Nat. Rev. Mater. 2018, 3, 18020. [CrossRef]

65. Cao, X.; Zhang, D.; Zhang, S.; Tao, Y.; Huang, W. Cn-containing donor-acceptor-type small-molecule materials for thermally activated delayed fluorescence oleds. J. Mater. Chem. C 2017, 5, 7699-7714. [CrossRef]

66. Im, Y.; Kim, M.; Cho, Y.J.; Seo, J.-A.; Yook, K.S.; Lee, J.Y. Molecular design strategy of organic thermally activated delayed fluorescence emitters. Chem. Mater. 2017, 29, 1946-1963. [CrossRef]

67. He, Z.; Cai, X.; Wang, Z.; Li, Y.; Xu, Z.; Liu, K.; Chen, D.; Su, S.-J. Sky-blue thermally activated delayed fluorescence material employing a diphenylethyne acceptor for organic light-emitting diodes. J. Mater. Chem. C 2018, 6, 36-42. [CrossRef]

68. Chatterjee, T.; Wong, K.-T. Perspective on host materials for thermally activated delayed fluorescence organic light emitting diodes. Adv. Opt. Mater. 2019, 7, 1800565. [CrossRef]

69. Im, Y.; Lee, J.Y. Recent progress of green thermally activated delayed fluorescent emitters. J. Inf. Disp. 2017, 18, 101-117. [CrossRef]

70. Wang, Y.-K.; Huang, C.-C.; Kumar, S.; Li, S.-H.; Dong, Z.-L.; Fung, M.-K.; Jiang, Z.-Q.; Liao, L.-S. Thermally activated delayed fluorescence sensitizer for $\mathrm{d}-\mathrm{a}-\mathrm{a}$ type emitters with orange-red light emission. J. Mater. Chem. C 2018, 6, 10030-10035. [CrossRef]

71. Cho, Y.J.; Jeon, S.K.; Chin, B.D.; Yu, E.; Lee, J.Y. The design of dual emitting cores for green thermally activated delayed fluorescent materials. Angew. Chem. Int. Ed. 2015, 54, 5201-5204. [CrossRef]

72. Furukawa, T.; Nakanotani, H.; Inoue, M.; Adachi, C. Dual enhancement of electroluminescence efficiency and operational stability by rapid upconversion of triplet excitons in oleds. Sci. Rep. 2015, 5, 8429. [CrossRef]

73. Uoyama, H.; Goushi, K.; Shizu, K.; Nomura, H.; Adachi, C. Highly efficient organic light-emitting diodes from delayed fluorescence. Nature 2012, 492, 234-238. [CrossRef] [PubMed]

74. Seino, Y.; Inomata, S.; Sasabe, H.; Pu, Y.-J.; Kido, J. High-performance green oleds using thermally activated delayed fluorescence with a power efficiency of over $100 \mathrm{~lm} \mathrm{w}^{-1}$. Adv. Mater. 2016, 28, 2638-2643. [CrossRef] [PubMed]

75. Gaj, M.P.; Fuentes-Hernandez, C.; Zhang, Y.; Marder, S.R.; Kippelen, B. Highly efficient organic light-emitting diodes from thermally activated delayed fluorescence using a sulfone-carbazole host material. Org. Electron. 2015, 16, 109-112. [CrossRef] 
76. Kim, O.Y.; Kim, B.S.; Lee, J.Y. High efficiency thermally activated delayed fluorescent devices using a mixed host of carbazole and phosphine oxide derived host materials. Synth. Met. 2015, 201, 49-53. [CrossRef]

77. Cho, Y.J.; Yook, K.S.; Lee, J.Y. A universal host material for high external quantum efficiency close to $25 \%$ and long lifetime in green fluorescent and phosphorescent oleds. Adv. Mater. 2014, 26, 4050-4055. [CrossRef] [PubMed]

78. Wong, M.Y.; Zysman-Colman, E. Purely organic thermally activated delayed fluorescence materials for organic light-emitting diodes. Adv. Mater. 2017, 29, 1605444. [CrossRef] [PubMed]

79. Lee, D.R.; Kim, B.S.; Lee, C.W.; Im, Y.; Yook, K.S.; Hwang, S.-H.; Lee, J.Y. Above 30\% external quantum efficiency in green delayed fluorescent organic light-emitting diodes. ACS Appl. Mater. Interfaces 2015, 7, 9625-9629. [CrossRef]

80. Komatsu, R.; Sasabe, H.; Seino, Y.; Nakao, K.; Kido, J. Light-blue thermally activated delayed fluorescent emitters realizing a high external quantum efficiency of $25 \%$ and unprecedented low drive voltages in oleds. J. Mater. Chem. C 2016, 4, 2274-2278. [CrossRef]

81. Volz, D. Review of organic light-emitting diodes with thermally activated delayed fluorescence emitters for energy-efficient sustainable light sources and displays. J. Photonics Energy 2016, 6, 020901. [CrossRef]

82. Tsai, W.-L.; Huang, M.-H.; Lee, W.-K.; Hsu, Y.-J.; Pan, K.-C.; Huang, Y.-H.; Ting, H.-C.; Sarma, M.; Ho, Y.-Y.; $\mathrm{Hu}, \mathrm{H} .-\mathrm{C}$; ; et al. A versatile thermally activated delayed fluorescence emitter for both highly efficient doped and non-doped organic light emitting devices. Chem. Commun. 2015, 51, 13662-13665. [CrossRef]

83. Braveenth, R.; Lee, H.; Kim, S.; Raagulan, K.; Kim, S.; Kwon, J.H.; Chai, K.Y. High efficiency green TADF emitters of acridine donor and triazine acceptor D-A-D structures. J. Mater. Chem. C 2019. [CrossRef]

84. Suzuki, K.; Adachi, C.; Kaji, H. Solution-processable thermally activated delayed fluorescence emitters for application in organic light emitting diodes. J. Soc. Inf. Disp. 2017, 25, 480-485. [CrossRef]

85. Hirata, S.; Sakai, Y.; Masui, K.; Tanaka, H.; Lee, S.Y.; Nomura, H.; Nakamura, N.; Yasumatsu, M.; Nakanotani, H.; Zhang, Q.; et al. Highly efficient blue electroluminescence based on thermally activated delayed fluorescence. Nat. Mater. 2014, 14, 330-336. [CrossRef] [PubMed]

86. Sato, K.; Shizu, K.; Yoshimura, K.; Kawada, A.; Miyazaki, H.; Adachi, C. Organic luminescent molecule with energetically equivalent singlet and triplet excited states for organic light-emitting diodes. Phys. Rev. Lett. 2013, 110, 247401. [CrossRef] [PubMed]

87. Mayr, C.; Lee, S.Y.; Schmidt, T.D.; Yasuda, T.; Adachi, C.; Brütting, W. Efficiency enhancement of organic light-emitting diodes incorporating a highly oriented thermally activated delayed fluorescence emitter. Adv. Funct. Mater. 2014, 24, 5232-5239. [CrossRef]

88. Serevičius, T.; Nakagawa, T.; Kuo, M.-C.; Cheng, S.-H.; Wong, K.-T.; Chang, C.-H.; Kwong, R.C.; Xia, S.; Adachi, C. Enhanced electroluminescence based on thermally activated delayed fluorescence from a carbazole-triazine derivative. Phys. Chem. Chem. Phys. 2013, 15, 15850-15855. [CrossRef] [PubMed]

89. Lee, D.R.; Kim, M.; Jeon, S.K.; Hwang, S.-H.; Lee, C.W.; Lee, J.Y. Design strategy for $25 \%$ external quantum efficiency in green and blue thermally activated delayed fluorescent devices. Adv. Mater. 2015, 27, 5861-5867. [CrossRef]

90. Yu, J.G.; Han, S.H.; Lee, H.L.; Hong, W.P.; Lee, J.Y. A novel molecular design employing a backbone freezing linker for improved efficiency, sharpened emission and long lifetime in thermally activated delayed fluorescence emitters. J. Mater. Chem. C 2019, 7, 2919-2926. [CrossRef]

91. Jung, M.; Lee, K.H.; Hong, W.P.; Lee, J.Y. The effect of frontier orbital distribution of the core structure on the photophysics and device performances of thermally activated delayed fluorescence emitters. J. Mater. Chem. C 2019. [CrossRef]

92. Kang, Y.J.; Yun, J.H.; Han, S.H.; Lee, J.Y. Benzofuroacridine and benzothienoacridine as new donor moieties for emission color management of thermally activated delayed fluorescent emitters. J. Mater. Chem. C 2019, 7, 4573-4580. [CrossRef]

93. Tanaka, H.; Shizu, K.; Miyazaki, H.; Adachi, C. Efficient green thermally activated delayed fluorescence (tadf) from a phenoxazine-triphenyltriazine (pxz-trz) derivative. Chem. Commun. 2012, 48, 11392-11394. [CrossRef] [PubMed]

94. Tanaka, H.; Shizu, K.; Nakanotani, H.; Adachi, C. Twisted intramolecular charge transfer state for long-wavelength thermally activated delayed fluorescence. Chem. Mater. 2013, 25, 3766-3771. [CrossRef] 
95. Shizu, K.; Uejima, M.; Nomura, H.; Sato, T.; Tanaka, K.; Kaji, H.; Adachi, C. Enhanced electroluminescence from a thermally activated delayed-fluorescence emitter by suppressing nonradiative decay. Phys. Rev. Appl. 2015, 3, 014001. [CrossRef]

96. Wada, Y.; Shizu, K.; Kubo, S.; Suzuki, K.; Tanaka, H.; Adachi, C.; Kaji, H. Highly efficient electroluminescence from a solution-processable thermally activated delayed fluorescence emitter. Appl. Phys. Lett. 2015, 107, 183303. [CrossRef] 